\title{
ANALISIS FAKTOR-FAKTOR YANG MEMPENGARUHI PENYERAPAN TENAGA KERJA PADA INDUSTRI KECIL DI KOTA BANDA ACEH
}

\author{
Riza Umary ${ }^{1}$, Abubakar Hamzah² ${ }_{\text {email: } \text { rizaumaryfoto@gmail.com }}^{\text {Said Musnadi }}{ }^{3}$ \\ ${ }^{1)}$ Dosen STIS Al-Aziziyah Sabang \\ ${ }^{2,3)}$ Dosen Fakultas Ekonomi dan Pascasarjana Universitas Syiah Kuala
}

\begin{abstract}
ABSTRAK
Permasalahan yang diangkat dalam thesis ini adalah faktor-faktor yang mempengaruhi tenaga kerja di Kota Banda Aceh. Tujuan dari penelitian ini adalah untuk mengetahui faktor-faktor yang mempengaruhi penyerapan tenaga kerja pada industri kecil di Kota Banda Aceh. Metode analisis yang digunakan dalam penelitian ini adalah regresi linier berganda. Analisis regresi ini kita gunakan untuk menguji model penyerapan tenaga kerja. Bermula dan spesifikasi model yang dibentuk berdasar teori yang ada atas suatu permasalahan sebagai mana dalam landasan teori, berupa penjabaran model. Data yang diperoleh dalam penelitian ini adalah data primer dan data sekunder. Hasil analisis menunjukkan Koefisien dari variabel upah dalam persamaan regsesi berganda bernilai negatif sebesar -7,158 hal ini menunjukkan bahwa setiap penurunan 1\% untuk upah maka akan meningkatkan jumlah penyerapan tenaga kerja sebesar $7,158 \%$. Koefisien dari variabel investasi dalam persamaan regsesi berganda bernilai positif sebesar 2,590 hal ini menunjukkan bahwa setiap kenaikan $1 \%$ untuk investasi maka akan meningkatkan jumlah penyerapan tenaga kerja sebesar 2,590\%. Koefisien dari variabel nilai produksi dalam persamaan regsesi berganda bernilai positif adalah 1,108 hal ini menunjukkan bahwa setiap kenaikan $1 \%$ untuk nilai produksi maka akan meningkatkan jumlah penyerapan tenaga kerja sebesar $1,108 \%$. Implikasi kebijakannya adalah agar pihak pemerintah memberikan kemudahan dalam meminjamkan modal untuk menambah modal agar meningkatnya nilai produksi. Pemerintah juga tidak menaikkan upah agar industri selalu cenderung menambah tenaga kerja.
\end{abstract}

Kata Kunci: Industri Kecil. Upah. Investasi. Nilai Produksi. Tenaga Kerja.

\begin{abstract}
Issues raised in this thesis are the factors that affect employment in the city of Banda Aceh. The aim of this study was to determine the factors that affect employment in small industry in Banda Aceh. The analytical method used in this research is multiple linear regression. This regression analysis we used to test the model of employment. Starting and model specifications established under the existing theories on an issue as to which the theoretical basis, in the form of translation models. The data obtained in this study are primary data and secondary data. The analysis showed wage coefficients of the variables in the equation regsesi multiple negative value of -7.158 indicating that each decrease of $1 \%$ for wage will increase the number of employment amounted to $7,158 \%$. Coefficients of the variables in the equation regsesi investment multiple positive value of 2.590 indicating that every increase of $1 \%$ for investment will increase the number of employment amounted to $2.590 \%$. Coefficients of the variables in the equation regsesi production value multiple positive value is 1,108 this shows that every $1 \%$ increase in production value will increase the number of employment amounted to $1.108 \%$. Policy implication is that the government provide ease in lending capital to increase the capital in order to increase the value of production. The government also did not raise wages so that the industry always tend to increase the workforce.
\end{abstract}

Keywords: Small industry, Wages. Investments. production cost, Labor.

\section{PENDAHULUAN}

Banda Aceh merupakan wilayah yang tidak memiliki lahan pertanian yang luas sehingga transformasi sektor ekonomi berbasis agraris menjadikan sektor industri sebagai leading sektor dalam perekonomian. Perindustrian di kota Banda Aceh lebih didominasi oleh industri berskala kecil. jumlah industri kecil di Banda Aceh Semakin bertambah jumlahnya, dari berbagai jumlah jenis industri kecil 
pada tahun 2007 berjumlah 5.083 industri dan terjadi peningkatan pada taun 2008 sebanyak 153 unit industri kecil, dan pada tahun 2009 bertambah 88 unit industri kecil menjadi 5.324 unit. Pada tahun 2010 bertambah sebanyak 157 unit menjadi 5.481 unit industri kecil, pada tahun 2011 bertambah sebanyak 320 unit menjadi 5.801, dan pada tahun 2012 bertambah sebanyak 60 unit menjadi 5.861 unit industri kecil (Sumber: BPS Provinsi Aceh). Jumlah industri kecil yang semakin meningkat seharusnya akan menjadi potensi untuk meningkatkan jumlah penyerapan tenaga kerja pada sektor tersebut.

pengaruh industri pengolahan terhadap PDRB kota Banda Aceh pada tahun 2010 adalah sebesar 2,01 \%, pada tahun 2011 adalah 1,95 \% dan pada tahun 2012 adalah sebesar 1,93 \% (Sumber: BPS Provinsi Aceh). kontribusi terhadap PDRB peranan industri kecil masih sangat minim. Hal ini menunjukkan produktivitas tenaga kerja pada industri kecil yang relatif masih rendah.disebabkan kontribusi pendapatan dari output industri kecil pada PDRB sangat rendah.

Sektor industri diyakini sebagai sektor yang dapat memimpin sektor-sektor lain dalam sebuah perekonomian menuju kemajuan. Produk-produk industrial selalu memiliki dasar tukar (terms of trade) yang tinggi atau lebih menguntungkan serta menciptakan nilai tambah yang lebih besar dibandingkan produk-produk sektor lain. Hal ini disebabkan karena sektor industri memiliki variasi produk yang sangat beragam dan mampu memberikan manfaat marjinal yang tinggi kepada pemakainya. Berusaha dalam bidang industri dan berniaga hasil-hasil industri juga lebih diminati karena proses produksi serta penanganan produknya lebih bisa dikendalikan oleh manusia. (Tohar, 2000)

Mengingat peranan penting sektor industri kecil dalam peningkatan pendapatan dan perluasan lapangan kerja di daerah pedesaan serta perkotaan, strategi pembangunan industri sebaiknya memberikan bantuan pada sektor ini untuk mengatasi masalah-masalah dalam industri kecil seperti produktivitas yang rendah, kesempatan kerja yang tersendat-sendat, keuangan dan lain-lain. Maka dari latar belakang diatas penulis tertarik meneliti dengan judul penelitian Analisis faktorfaktor yang mempengaruhi penyerapan tenaga kerja pada industri kecil di Kota Banda Aceh.

\section{STUDI KEPUSTAKAAN}

\section{Pengertian Usaha Kecil}

Menurut Tohar (2000:15) usaha kecil adalah bentuk ekonomi rakyat yang berskala kecil dan memenuhi kriteria kekayaan bersih atau hasil penjualan tahunan serta kepemilikan sebagaimana diatur dalam Undang-undang No. 20 tahun 
2008. Definisi-definisi usaha kecil dapat dijelaskan sebagai berikut:

a. Memiliki kekayaan bersih lebih dari Rp. 50.000.000,00 (lima puluh juta rupiah) sampai dengan paling banyak Rp. 500.000.000,00 (lima ratus juta rupiah) tidak termasuk tanah dan bangunan tempat usaha.

b. Memiliki hasil penjualan lebih dari Rp. 300.000.000,00 (tiga ratus juta rupiah) sampai dengan paling banyak Rp. 2.500.000.000 (dua milyar lima ratus juta rupiah)Berdasarkan total penjualan bersih per tahun.(Tohar, 2000)

\section{Teori Produksi}

Produksi dalam arti ekonomi mempunyai pengertian semua kegiatan yang meningkatkan nilai kegunaan atau faedah (utility) suatu benda.Ini dapat berupa kegiatan yang meningkatkan kegunaan dengan mengubah bentuk atau menghasilkan barang baru (utility of form). Dapat pula meningkatnya kegunaan suatu benda itu karena adanya kegiatan yang mengakibatkan dapat berpindahnya suatu benda dari tangan seseorang ke tangan orang lain(Sriyadi, 1995) Produksi sering digunakan dalam istilah membuat sesuatu, dalam istilah yang lebih luas dan lebih fundamental, produksi diarahkan sebagai pengubahan bahan-bahan dari sumbersumber menjadi hasil yang diinginkan konsumen yang berupa barang dan jasa. (Swastha, Basudan Sukotjo, 1997). Produksi menurut Beattie merupakan proses kombinasi dan koordinasi material-material dan kekuatan, seperti kekuatan input, faktor sumberdaya, atau jasa-jasa produksi dalam pembuatan suatu barang atau jasa.

\section{Teori Biaya}

Biaya adalah kas atau nilai ekuivalen kas yang dikorbankan untuk barang atau jasa yang diharapkan membawa keuntungan masa ini dan masa datang untuk organisasi. $^{2}$

Menurut Sriyadi biaya adalah pengorbanan yang rasional, yang seharusnya dapat diduga lebih dahulu dan tidak dapat dihindarkan, yang dapat dihitung dengan nilai uang dan yang berhubungan dengan produksi barang dan jasa. $^{3}$

\footnotetext{
${ }^{\mathrm{l}}$ Beattie, Bruce R, dan C. Robert Taylor.1994. Ekonomi Produksi. Yogyakarta : Gajahmada University Press.
}

${ }^{2}$ Hansen and Mowen, diterjemahkan oleh Purwatiningsih; Manajemen Biaya; Edisi 1; (Jakarta; Penerbit Salemba Empat, 2000), hal. 28

${ }^{3}$ Sriyadi, Sriyadi. Pengantar Ilmu Perusahaan Modern, (Jakarta: Dirjen Dikti, 1995) 
Biaya produksi diartikan sebagai keseluruhan faktor produksi yang dikorbankan dalam proses produksi. Sebagian ahli ekonomi kemudian mengatakan bahwa biaya produksi adalah keseluruhan biaya yang dikorbankan untuk menghasilkan produk hingga produk itu sampai di pasar, atau sampai ke tangan konsumen. Dengan demikian biaya angkut, biaya penyimpanan di gudang, dan biaya iklan yang menunjang proses produksi hingga produk itu sampai ke tangan konsumen, dapat dikategorikan biaya produksi ${ }^{4}$.

\section{Fungsi Investasi}

Mulyadi $^{5}$ menyatakan bahwa: "Investasi adalah pengaitan sumber-sumber dalam jangka panjang untuk menghasilkan laba di masa yang akan datang". Investasi dapat diartikan sebagai penanaman modal dalam suatu kegiatan yang memiliki jangka waktu relatif panjang dalam berbagai bidang usaha. Penanaman modal yang ditanamkan dalam arti sempit berupa proyek tertentu baik bersifat fisik atau pun non fisik, seperti proyek pendirian pabrik,

\footnotetext{
${ }^{4}$ Ahman, Eeng. 2004.

Ekonomi.Bandung : Grafindo Media Pratama

${ }^{5}$ Mulyadi, Akuntansi Biaya Edisi ke-5, (Yogyakarta: BP-STIE YKPN, 2001), hal. 284
}

jalan, jembatan, pembangunan gedung dan proyek penelitian, dan pengembangan. Sukirno mengartikan bahwa investasi sebagai pengeluaran-pengeluaran untuk membeli barang-barang modal dan peralatan-peralatan produksi dengan tujuan untuk mengganti dan terutama menambah barang-barang modal dalam perekonomian yang akan digunakan untuk memproduksikan barang dan jasa di masa depan. ${ }^{6}$

Investasi bertujuan untuk meningkatkan produksi dan produktifitas yang lebih tinggi yang akan mengakibatkan surplus yang lebih besar, sehingga mempengaruhi proses investasi pada sektor yang satu atau yang lainnya. Dengan begitu kesempatan kerja semakin meningkat sehingga mempengaruhi penyerapan tenaga kerja.Investasi dianggap mempunyai pengaruh terhadap perkembangan sektor industri yang berunjung kepada terbukanya kesempatan kerja sehingga dapat mengurangi tingkat pengangguran. Investasi merupakan salah satu faktor yang dapat mempengaruhi permintaan tenaga kerja.Sehingga dapat dilihat persamaan matematisnya ${ }^{7}$.

\footnotetext{
${ }^{6}$ Sukirno, Mikro Ekonomi Teori
} Pengantar. Edisi Ketiga, (Jakarta: Rajagrafindo Persada, 2006), hal 19

\footnotetext{
${ }^{7}$ Karib, Abdul. 2012. Analisis Pengaruh Produksi, Investasi, dan Unit Usaha terhadap Penyerapan Tenaga Kerja pada Sektor Industri di Sumatera
} 


\section{Pengertian Tenaga Kerja (Labor)}

Tenaga kerja adalah faktor produksi yang terdiri dari semua kontribusi fisik dan mental yang disediakan orang. Istilah tenaga kerja manusia (labor) dalam ilmu ekonomi bukanlah semata-mata kekuatan manusia untuk mencangkul, mengergaji, bertukang, dan kegiatan fisik lainnya. Hal yang dimaksud di sini memang bukanlah sekedar labor atau tenaga kerja saja. Tetapi lebih luas lagi, yaitu human resources (sumber daya manusia).

Sumber daya manusia jelas lebih luas artinya dari pada hanya sekedar tenaga kerja saja. Istilah sumber daya manusia itu, tidak saja mencakup tenaga fisik atau tenaga jasmani manusia tetapi juga kemampuan mental atau kemampuan non fisiknya, baik tenaga terdidik maupun tenaga yang tidak terdidik, tidak saja tenaga yang terampil tetapi tenaga yang tidak terampil. Artinya di dalam istilah atau pengertian sumber daya manusia itu kumpulan semua atribut atau kemampuan manusiawi yang dapat disumbangkan untuk memungkinkan di lakukannya proses produksi barang dan jasa. Oleh karena itu, bahwa kualitas atau sumber daya manusia sesuatu bangsa itu

Barat. Jurnal Manajemen dan Kewirausahaan Vo.3 No. 3 ISSN. 20865031 tergantung pada kualitas atau mutu ketaqwaan, kekuatan fisik, pendidikan, serta kecakapan penduduknya. ${ }^{8}$

Angkatan kerja dan tenaga kerja menurut (Noor, 2007;469) adalah istilah yang hampir sama dengan arti yang berbeda. Pengertian kedua istilah tersebut adalah sebagai berikut: Angkatan kerja adalah penduduk dengan umur produktif atau penduduk yang berumur 15 tahun keatas, kecuali ibu rumah tangga, dan penduduk yang lagi mengikuti pendidikan. Sedangkan tenaga kerja adalah angkatan kerja yang bekerja minimal 36 jam seminggu. Biasanya makin sejahtera suatu bangsa, jam kerjanya makin pendek.

\section{METODE PENELITIAN}

Penelitian ini bertujuan untuk mengetahui faktor-faktor yang mempengaruhi Penyerapan tenaga kerja pada industri kecil di Kota Banda Aceh. Penelitian ini membatasi ruang lingkupnya pada industri kecil makanan dan minumam baik formal maupun non formal dan mengambil lokasi penelitian pada Industri Kecil di Kota Banda Aceh, Provinsi Aceh.

Jenis data yang digunakan dalam penelitian ini adalah data primer dan sekunder. Data primer merupakan data yang diperoleh langsung dari lapangan,

\footnotetext{
${ }^{8}$ Rosyidi, Suherman, Pengatar Teori
}

Ekonomi, (Jakarta : PT. Raja Grafindo Persada, 2006), hal. 56 
interview langsung pada responden maupun melalui daftar pertanyaan (kuisioner) yang diberikan kepada pemilik usaha kecil. Data sekunder merupakan data yang bersumber dari publikasi pada berbagai instansi pemerintah, antara lain Badan Pusat Statistik (BPS) Provinsi Aceh. Dinas Perindustrian, Perdagangan, Koperasi dan UKM Kota Banda Aceh dan instansiinstansi terkait lainnya yang berhubungan dengan penelitian ini.

Metode analisis yang digunakan dalam penelitian ini adalah regresi linier berganda. Analisis regresi ini kita gunakan untuk menguji model penyerapan tenaga kerja. Bermula dan spesifikasi model yang dibentuk berdasar teori yang ada atas suatu permasalahan sebagai mana dalam landasan teori, berupa penjabaran model.

Berdasarkan penelitian sebelumnya maka perumusan model fungsi penyerapan tenaga kerja yang digunakan dalam penelitian ini adalah:

$\mathrm{Y}=\beta_{0} \cdot X_{1}{ }^{\beta 1} \cdot X_{2}{ }^{\beta 2} \cdot e^{\varepsilon}$

dapat dinyatakan sebagai berikut :

$\operatorname{Ln} Y=\operatorname{Ln} \beta 0+\beta 1 \operatorname{Ln} X 1+\beta 2 \operatorname{Ln} X 2+\varepsilon$

dimana:

$Y=$ jumlah tenaga kerja

$\mathrm{Xl}=\mathrm{Upah}$

$\mathrm{X} 2=$ Nilai investasi

X3 = Nilai Produksi

$\beta \mathrm{o}=$ intersep

$\beta 1, \beta 2, \beta 3,=$ koefisien regresi parsial $\varepsilon=$ faktor pengganggu (distubance error).

Beberapa variabel yang telah digunakan untuk kepentingan penelitian ini memiliki konsep dan definisi sebagai berikut:

a) Upah

Adalah biaya yang dikeluarkan pengusaha industri kecil untuk membayar upah tenaga kerja dalam satu bulan yang dihitung dalam rupiah.

b) Nilai Investasi

Adalah satuan nilai pembelian pengusaha atas barangbarang modal (mesin dan peralatan) dan pembelanjaan untuk persediaan industri kecil dan menengah selama satu tahun di Kota Banda Aceh yang diukur dalam rupiah.

c) Nilai Produksi

Yaitu nilai dari barang dan jasa yang dihasilkan oleh seluruh industri kecil yang ada di Kota Banda Aceh dengan satuan rupiah.

d) Penyerapan Tenaga Kerja

Adalah sejumlah tenaga kerja yang bekerja atau dipekerjakan oleh pengusaha dalam memproduksi barang pada sektor industri kecil selama satu tahun dengan satuan orang. 
Nilai Produksi

Nilai produksi industri kecil antara Rp.3.000.000-Rp.4.999.000 adalah sebanyak 6 responden (8 persen) dan nilai produksi industri kecil antara Rp. 5.000.000-9.999.000 adalah 11 responden (14 persen), kemudian nilai produksi industri kecil antara Rp.10.000.000Rp.19.999.000 adalah 51 responden (66 persen) dari total sampel, nilai produksi industri kecil antara Rp.20.000.000Rp.49.999.000 adalah 4 responden (5 persen) dari total sampel dan nilai produksi industri kecil di atas Rp.50.000.000 adalah 5 responden (16 persen).

\section{Nilai Investasi}

Nilai investasi industri kecil antara Rp.100.000-Rp.499.000 adalah sebanyak 18 responden (23 persen) dan nilai investasi industri kecil antara Rp. 500.000-999.000 adalah 7 responden ( 9 persen), kemudian nilai investasi industri kecil antara Rp.1.000.000-Rp.1.999.000 adalah 31 responden (40 persen) dari total sampel, nilai investasi industri kecil antara Rp.2.000.000-Rp.4.999.000 adalah 17 responden (22 persen) dari total sampel dan nilai investasi industri kecil di atas Rp.5.000.000 adalah 4 responden (5 persen).
Upah industri kecil antara Rp.500.000-Rp.999.000 adalah sebanyak 18 responden (23 persen) dan upah industri kecil antara Rp. 1.000.000-1.999.000 adalah 7 responden (9 persen), kemudian upah industri kecil antara Rp.2.000.000Rp.2.999.000 adalah 30 responden (39 persen) dari total sampel, upah industri kecil antara Rp.3.000.000-Rp.3.999.000 adalah 16 responden (21 persen), upah industri kecil antara Rp.4.000.000Rp.4.999.000 adalah 3 responden (4 persen) dari total sampel dan upah industri kecil di atas Rp.5.000.000 adalah 3 responden (4 persen).

\section{ANALISIS REGRESI}

\section{Tabel IV-8}

\section{Coefficients $^{\mathrm{a}}$}

\begin{tabular}{|c|c|c|c|c|c|}
\hline \multirow[b]{2}{*}{ Model } & \multicolumn{2}{|c|}{$\begin{array}{l}\text { Unstandardize } \\
\text { d Coefficients }\end{array}$} & $\begin{array}{l}\text { Stand } \\
\text { ardize } \\
\text { Coeffi } \\
\text { cients }\end{array}$ & & \\
\hline & $B$ & $\begin{array}{l}\text { Std. } \\
\text { Error }\end{array}$ & Beta & $t$ & Sig. \\
\hline $\begin{array}{l}1 \text { (Cons } \\
\text { ) }\end{array}$ & 1.542 & .140 & & 11.009 & $\begin{array}{l}.00 \\
0\end{array}$ \\
\hline $\mathrm{W}$ & $-7.158 \mathrm{E}-7$ & .000 & 1.404 & 12.723 & .00 \\
\hline
\end{tabular}




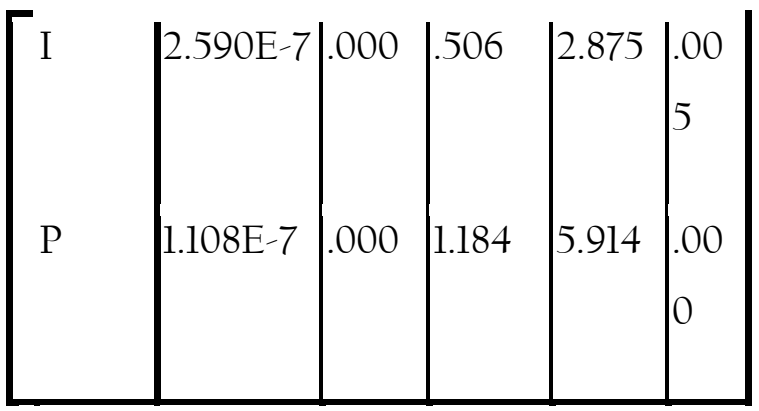

a. Dependent Variable: L

Dari tabel di atas kemudian dimasukkan dalam persamaan regresi:

$\operatorname{Ln} Y=\operatorname{Ln} \beta 0+\beta 1 \operatorname{LnX} 1+\beta 2 \operatorname{LnX} 2+\beta 3 \operatorname{LnX} 3+\varepsilon$

$\operatorname{LnY}=1,542$ -

$7,158 \operatorname{Ln} X_{1}+2,590 \operatorname{Ln} X_{2}+1,108 \operatorname{Ln} X_{3}+\mu$

Dari persamaan regresi berganda diatas dapat kita ketahui bahwa:

1. Koefisien dari variabel upah dalam persamaan regsesi berganda bernilai positif sebesar 7,158 hal ini menunjukkan bahwa setiap kenaikan $1 \%$ untuk upah maka akan meningkatkan jumlah penyerapan tenaga kerja sebesar 7,158\%.

2. Koefisien dari variabel investasi dalam persamaan regsesi berganda bernilai positif sebesar 2,590 hal ini menunjukkan bahwa setiap kenaikan $1 \%$ untuk investasi maka akan meningkatkan jumlah penyerapan tenaga kerja sebesar $2,590 \%$.

3. Koefisien dari variabel nilai produksi dalam persamaan regsesi berganda bernilai positif adalah
1,108 hal ini menunjukkan bahwa setiap kenaikan $1 \%$ untuk nilai produksi maka akan meningkatkan jumlah penyerapan tenaga kerja sebesar $1,108 \%$.

\section{KESIMPULAN}

a. Hasil penelitian menyatakan bahwa variabel Upah, Nilai Investasi dan Nilai Produksi berpengaruh signifikan terhadap penyerapan tenaga kerja di Kota Banda Aceh.

b. Koefisien dari variabel upah dalam persamaan regsesi berganda bernilai negatif sebesar $-7,158$ hal ini menunjukkan bahwa setiap penurunan $1 \%$ untuk upah maka akan meningkatkan jumlah penyerapan tenaga kerja sebesar 7,158\%. Koefisien dari variabel investasi dalam persamaan regsesi berganda bernilai positif sebesar 2,590 hal ini menunjukkan bahwa setiap kenaikan $1 \%$ untuk investasi maka akan meningkatkan jumlah penyerapan tenaga kerja sebesar 2,590\%. Koefisien dari variabel nilai produksi dalam persamaan regsesi berganda bernilai positif adalah 1,108 hal ini menunjukkan bahwa setiap kenaikan $1 \%$ untuk nilai produksi maka akan meningkatkan jumlah penyerapan tenaga kerja sebesar $1,108 \%$. 


\section{SARAN}

1. Untuk meningkatkan permintaan tenaga kerja dapat dilakukan dengan meningkatkan investasi supaya bertambahnya jumlah produksi sehingga dapat membantu dalam penyerapan tenaga kerja pada Industi Kecil di Kota Banda Aceh.

2. Pemerintah atau pihak Bank atau lembaga non keuangan seharusnya lebih memprioritaskan untuk meminjamkan modal kepada para pengusaha agar para pengusaha dapat mengembangkan usahanya baik dalam bentuk kredit atau yang lain.

\section{DAFTAR PUSTAKA}

Ahman, Eeng. 2004. Ekonomi.Bandung : Grafindo Media Pratama

Beattie, Bruce R, dan C. Robert Taylor.1994. Ekonomi Produksi. Yogyakarta : Gajahmada University Press.

Karib, Abdul. 2012. Analisis Pengaruh Produksi, Investasi, dan Unit Usaha terhadap Penyerapan Tenaga Kerja pada Sektor Industri di Sumatera Barat. Jurnal Manajemen dan Kewirausahaan Vo.3 No. 3 ISSN. 2086- 5031
Tohar, Membuka Usaha Kecil, (Yogyakarta:

Penerbit Kamisius. 2000)

Sriyadi. Pengantar Ilmu Perusahaan Modern, (Jakarta: Dirjen Dikti, 1995)

Hansen and Mowen, diterjemahkan oleh Purwatiningsih; Manajemen Biaya; Edisi l; (Jakarta; Penerbit Salemba Empat, 2000)

Mulyadi, Akuntansi Biaya Edisi ke-5, (Yogyakarta: BP-STIE YKPN, 2001)

Noor, H.F. (2007), Ekonomi Manajerial, Rajawali Pers, Jakarta

Sukirno, Mikro Ekonomi Teori Pengantar. Edisi Ketiga, (Jakarta: Rajagrafindo Persada, 2006)

Swastha, Basu dan Sukotjo, Ibnu. 1997. Pengantar Bisnis Modern. Yogyakarta : BPFE.

Rosyidi, Suherman, Pengatar Teori Ekonomi, (Jakarta: PT. Raja Grafindo Persada, 2006) 